\title{
A Comparison of the Success of Native and Transfer Private Pilots at Southern Illinois University Carbondale
}

\author{
Michael F. Robertson and Bryan T. Harrison \\ Southern Illinois University Carbondale
}

\begin{abstract}
This study seeks differences in the degree completion and time-to-degree of native versus transfer private pilots along with transfer private pilots required to take proficiency training versus those who did not take proficiency training before beginning the aviation flight program at Southern Illinois University Carbondale (SIUC). An ex-post facto descriptive study of 338 flight students that began commercial pilot training between the fall 1998 through the summer 2003 semesters measured completion or exit from the SIUC flight program. The study population was determined from the Student Information System and the data on degree completion and time-to-degree was gathered from the students' flight training records. Chi-squares were used to determine significance $(\mathrm{p}<.05)$ in degree completion percentages and t-tests were used to determine days-to-degree significance $(\mathrm{p}<.05)$. The study concludes that there are no significant differences between native and transfer or proficiency and direct-entry private pilots at SIUC.
\end{abstract}

\section{INTRODUCTION}

Currently, to enter the flight program at Southern Illinois University Carbondale (SIUC), students must apply to the Aviation Flight Program in addition to applying to the university. Students can enter the Aviation Flight Program with or without their private pilot's license. Currently, if students already possess a private pilot's license, they begin by taking the Private Pilot Transition Course, which is a 10-14 flight hour refresher/evaluation course. Once this course is successfully completed, they can proceed directly into instrument training and receive university credit for their private pilot's license. If higher certificates are held, entrants will only be given credit for their private pilot's license. Students that begin without a private pilot's license take Primary Flight I and Primary Flight II. Once these two courses are completed, the students receive their private pilot's license. The students will then take three courses beginning with their instrument training and time building towards their commercial certificate. After this training is complete, they take a course to receive their commercial certificate and then take the last course to obtain their multi-engine rating.

Prior to the creation of the Private Pilot Transition Course in the fall of 2005, the flight department's policy varied yearly either requiring transfer private pilots to take proficiency training before beginning instrument training or allowing them to enter directly into the initial instrument training course. From the fall 1998 semester to the spring 2001 semester, most private pilot transfers were required to take up to ten hours of proficiency training before beginning instrument training. Some exceptions to this policy were allowed if the transfer students had previously taken their private pilot check ride with an Assistant Professor Emeritus from the flight program. From the summer of 2001 until summer of 2003, private pilot transfer students began training by enrolling directly into the initial instrument training course. From the fall of 2003 until the summer of 2005, private pilot transfer students were required to take Primary Flight II before beginning instrument training.

Private Pilot Certificate status upon program entry into the Aviation Flight Program may affect student retention, degree completion and time-to-degree. Student retention and degree completion are two major issues facing any academic program. These issues can effect students' decisions as to where to receive their training and administrative decisions about program funding.

If students start flight training in their sophomore or junior year or spend extra time in their earlier flight courses, they may complete their Bachelor of Science in Aviation Management before their Associate of Applied Science in Aviation Flight. In this case, students 
may not be willing to stay at the university when they could finish their flight training elsewhere. If students enter the flight program with their private pilot's certification, they may be able to complete their degree faster because they can bypass the private pilot training. However, transfer students generally come from an unknown training background and may have issues assimilating to the program.

One of the major issues facing the future of commercial aviation is the demand for quality trained airline pilots. In the past, the major airlines relied heavily on military trained pilots. With the military downsizing in the last three decades, there are fewer military trained pilots available, leaving the void to be filled with civilian trained pilots. (Hansen \& Oster, 1997)

A university's key to balancing the high demand for quality pilots is efficiency. If completion rates or the time-to-degree can be improved, more students can be trained without increasing instructional staff or enlarging the aircraft fleet. Efficiency can be achieved by reviewing current practices and making adjustments to the program's structure that will help the program survive into the future.

\section{RESEARCH QUESTIONS}

1. Is there a difference in the successful completion of instrument flight training between students who earn their private pilot's license at the university and those who complete their private pilot training elsewhere?

2. Is there a difference in the successful completion of multi-engine training between students who earn their private pilot's license at the university and those who complete their private pilot training elsewhere?

3. Is there a difference in days-to-degree between students that complete their private pilot's license at the university and those who complete their private pilot training elsewhere?

4. Is there a difference in the successful completion of instrument flight training between transfer private pilots who enter directly into instrument training and those whom must take proficiency or evaluation training?
5. Is there a difference in the successful completion of multi-engine training between transfer private pilots who enter directly into instrument training and those whom must take proficiency or evaluation training?

6. Is there a difference in days-to-degree between transfer private pilots who enter directly into instrument training and those whom must take proficiency or evaluation training?

\section{BACKGROUND}

\section{FAA Part 61 Versus 141 Training}

According to the Federal Aviation Regulations, when students receive training for any type of pilot certificate or rating, they have the choice of pursuing their training through two types of flight schools: Part 61 or Part 141. SIUC is a Part 141 flight school. Private pilots that transfer to the university may come from either a Part 61 or a Part 141 flight schools. A Part 141 school has an Air Agency Certificate issued by the FAA and may be authorized to give their students practical exams. As of 2003, there were 506 FAA Part 141 certificated pilot schools in the United States (U.S. Department of Transportation, 2003). At a Part 141 school the FAA approves all lessons, whereas a Part 61 school requires pilots to cover general subject areas and meet a minimum number of flight hours. No matter which part program students train under, they receive the same pilot certificates. The difference between Part 61 and Part 141 flight schools is in the structure of the training.

The FAA's Airplane Flying Handbook explains the requirements and some benefits of Part 141 certificated schools:

The school must operate in accordance with an established curriculum, which includes a training course outline (TCO) approved by the FAA. The TCO must contain student enrollment prerequisites, detailed description of each lesson including standards and objectives, expected accomplishments and standards for each stage of training, and a description of the checks and tests used to measure a student's accomplishments. FAA-approved pilot school certificates 
must be renewed every 2 years. Renewal is contingent upon proof of continued high quality instruction and a minimum level of instructional activity. (U.S. Department of Transportation, 2004, pp. $1-4 \& 1-5)$

The Airplane Flying Handbook also states that most pilot schools are Part 61 and that "many of these non-certificated schools provide excellent training that meets or exceeds the standards required of FAA-approved pilot schools" (p. 14). The handbook states that the flight instructors at both types of schools must meet the same certification and renewal standards and that, "any training program is dependent upon the quality of the ground and flight instruction a student pilot receives" (p. 1-4).

An article on the Student Pilot Network website (Part 61 Versus Part 141, 2002) stated that Part 61 is the flexible choice of pilot training compared to Part 141 as the structured choice. The article claimed that Part 61 schools can be very motivating and enjoyable, but if the training is poorly organized, it may take longer to complete; whereas, Part 141 schools are more structured because they must adhere to more regulations that guarantee coverage of specific subject areas and require more stage check rides during training. The article concluded that the quality of training depends more on the quality of the instructor and the student/instructor relationship than whether the training is done in a Part 141 or 61 environment (Part 61 Versus Part 141, 2002).

In a discussion forum following the previous article on the Student Pilot Network, John C. Boylls a designated pilot examiner, who was awarded the FAA Western-Pacific Region Flight Instructor of the Year in 1998 and has formerly developed training courses for the King Schools, gave his opinion on Part 61 and Part 141. Boylls believes that Part 141 school does not necessarily guarantee better training and that it depends upon the management of the flight school and their integrity. He also noted one downside to Part 141 schools is that instructors usually come from the schools where they were trained, keeping those schools isolated from outside ideas (Part 61 Versus Part 141, 2002).

\section{METHODS AND PROCEDURES}

\section{Study Population and Sampling Procedures}

The study population includes all aviation flight students at Southern Illinois University Carbondale that began instrument training between the fall 1998 semester and the summer 2003 semester. Using the information gathered by the Student Information System (SIS) at the university, the course lists revealed that 338 flight students were enrolled in the beginning instrument training course over the study's time period. Upon further review, two students enrolled in the course twice, making 336 students in the population. Using archival data, information was found on all 336 students. For the purpose of this study, a native student will be defined as a student that received his/her private pilot's license at the university. A transfer student will be defined as a student that received his/her private pilot's license anywhere other than the university. A direct-entry transfer student will be defined as a transfer flight student that entered instrument training without any proficiency training or testing. A proficiency transfer student will be defined as a transfer flight student that was required to complete proficiency training or testing at the university before entering instrument training.

\section{Limitations of the Study}

The study cannot determine the quality or location of private pilot training that students receive outside of SIUC or the reasons for students leaving the program prior to instrument rating or degree completion. The study cannot determine the amount of previous flight training; the study can only determine if the student has a private pilot's license prior to program acceptance. Days-to-degree will not take into consideration weekends or breaks in training in which the student does not fly.

Data was collected on all students that began instrument training over a five-year period from the fall 1998 semester to the summer 2003 semester. The end date of 2003 was selected to allow students at least three years to complete the A.A.S. degree. Students who enroll in instrument training and fail to complete the A.A.S. degree or reach the instrument training course will be counted as incomplete. The length of time-to-degree 
completion will be measured in days from the first day of flight or ground training in the initial instrument training course until the day that multi engine training is completed. The completion of multi engine training was used to determine degree completion since it is the last flight course in the sequence of flight courses needed to attain the associate degree.

\section{Measures}

The data concerning the location of private pilot training, start date and completion date was gathered from SIS and the students' progress charts (training records). The flight department's semester report of student training was also referred to in the case of missing progress charts. The semester report is an administrative document that lists the course start date and pass/fail/withdrawal date of flight students.

\section{Data Analysis}

Descriptive statistics were used to describe the study population. Frequency counts and percentages of completion were utilized to analyze certificate status at enrollment and entry method into the flight program. Descriptive statistics were also used to determine days-todegree for students that completed the program.

Inferential statistics were used to test the research questions. Chi-square was used to test for significant differences between native and transfer students' completion of instrument training and multi-engine training. A t-test of independent samples was used to determine significant differences in days-to-degree of native and transfer students. Chi-square was also used to test for significant differences between direct and proficiency transfer students' completion of instrument training and multiengine training. A t-test of independent samples was used to determine significant differences in days-to-degree of direct and proficiency transfer students.

\section{RESULTS}

\section{Treatment of Data}

The data was imported into SPSS 11 for Windows (Statistical Procedures for the Social Sciences) to assist in analyzing the data. SPSS was used to calculate descriptive statistics such as frequencies, completion percentages, standard deviations and days-to-degree. The program was also used to calculate chi-squares and t-tests for independent samples.

The first eight tables use descriptive statistics to explain the study's population. The last six tables use chi-squares and t-tests to test for significance at the .05 level.

\section{Presentation of Data}

Table 1 displays the study population separated by native and transfer private pilots. Semesters of enrollment are listed in chronological order, with native pilots referring to pilots that completed their private pilot training at SIUC and transfer pilots being pilots that completed their training elsewhere. For the study population, there were 336 students that began instrument training during the identified period, of which 202 were native and 134 were transfer private pilots. From year-to-year, the highest student enrollments in the initial instrument training course were in the fall semesters. Normally, there was a higher native student enrollment than transfer student enrollment in this course with the exceptions of summer 2000, fall 2000, summer 2001 and fall 2001.

Table 2 displays the instrument training completion rate of native and transfer students by semester. Native students had a $67 \%$ rate of completion with 136 of the 202 students completing instrument training. Transfer students had a slightly higher rate of completion at $70 \%$ with 94 of the 134 students completing instrument training.

Table 3 displays multi-engine training completion rate of native and transfer students by semester. There was a $49 \%$ completion rate for native students with 97 of the 202 students completing their multi-engine training. Transfer students in this course had a slightly higher rate of completion at $54 \%$, with 72 of the 134 students completing the course. When the data was collected, there were four students either still active in or waiting to begin multi-engine training. The four students were subtracted from the total enrolled after the completion percentages were calculated. 
Table 1. Number of Native and Transfer Students Enrolled by Semester

\begin{tabular}{lccc}
\hline Semester & Native & Transfer & Total \\
\hline Fall 1998 & 27 & 13 & 40 \\
Spring 1999 & 20 & 9 & 29 \\
Summer 1999 & 2 & 2 & 4 \\
Fall 1999 & 22 & 19 & 41 \\
Spring 2000 & 19 & 5 & 24 \\
Summer 2000 & 2 & 4 & 6 \\
Fall 2000 & 11 & 12 & 23 \\
Spring 2001 & 17 & 1 & 18 \\
Summer 2001 & 0 & 3 & 3 \\
Fall 2001 & 7 & 26 & 33 \\
Spring 2002 & 19 & 6 & 25 \\
Summer 2002 & 8 & 7 & 15 \\
Fall 2002 & 23 & 16 & 39 \\
Spring 2003 & 21 & 11 & 32 \\
Summer 2003 & 4 & 0 & 4 \\
\hline Totals & 202 & 134 & 336 \\
\hline
\end{tabular}

Table 2. Instrument Training Completion Rate of Native and Transfer Students by Semester

\begin{tabular}{|c|c|c|c|c|}
\hline Semester & Transfer Status & Enrolled & Completed & $\%$ Complete \\
\hline \multirow[t]{2}{*}{ Fall 1998} & Native & 27 & 20 & $74 \%$ \\
\hline & Transfer & 13 & 9 & $69 \%$ \\
\hline \multirow[t]{2}{*}{ Spring 1999} & Native & 20 & 12 & $60 \%$ \\
\hline & Transfer & 9 & 5 & $56 \%$ \\
\hline \multirow[t]{2}{*}{ Summer 1999} & Native & 2 & 2 & $100 \%$ \\
\hline & Transfer & 2 & 2 & $100 \%$ \\
\hline \multirow[t]{2}{*}{ Fall 1999} & Native & 22 & 12 & $55 \%$ \\
\hline & Transfer & 19 & 13 & $68 \%$ \\
\hline \multirow[t]{2}{*}{ Spring 2000} & Native & 19 & 14 & $74 \%$ \\
\hline & Transfer & 5 & 5 & $100 \%$ \\
\hline \multirow[t]{2}{*}{ Summer 2000} & Native & 2 & 1 & $50 \%$ \\
\hline & Transfer & 4 & 3 & $75 \%$ \\
\hline \multirow[t]{2}{*}{ Fall 2000} & Native & 11 & 6 & $55 \%$ \\
\hline & Transfer & 12 & 5 & $42 \%$ \\
\hline \multirow[t]{2}{*}{ Spring 2001} & Native & 17 & 14 & $82 \%$ \\
\hline & Transfer & 1 & 1 & $100 \%$ \\
\hline \multirow[t]{2}{*}{ Summer 2001} & Native & 0 & 0 & \\
\hline & Transfer & 3 & 2 & $67 \%$ \\
\hline
\end{tabular}


Table 2. Instrument Training Completion Rate of Native and Transfer Students by SemesterContinued

\begin{tabular}{|c|c|c|c|c|}
\hline$\underline{\text { Semester }}$ & Transfer Status & Enrolled & Completed & $\%$ Complete \\
\hline \multirow[t]{2}{*}{ Fall 2001} & Native & 7 & 5 & $71 \%$ \\
\hline & Transfer & 26 & 19 & $73 \%$ \\
\hline \multirow[t]{2}{*}{ Spring 2002} & Native & 19 & 17 & $89 \%$ \\
\hline & Transfer & 6 & 4 & $67 \%$ \\
\hline \multirow[t]{2}{*}{ Summer 2002} & Native & 8 & 5 & $63 \%$ \\
\hline & Transfer & 7 & 5 & $71 \%$ \\
\hline \multirow[t]{2}{*}{ Fall 2002} & Native & 23 & 14 & $61 \%$ \\
\hline & Transfer & 16 & 12 & $75 \%$ \\
\hline \multirow[t]{2}{*}{ Spring 2003} & Native & 21 & 11 & $52 \%$ \\
\hline & Transfer & 11 & 9 & $82 \%$ \\
\hline \multirow[t]{2}{*}{ Summer 2003} & Native & 4 & 3 & $75 \%$ \\
\hline & Transfer & 0 & 0 & \\
\hline \multirow[t]{2}{*}{ Totals } & Native & 202 & 136 & $67 \%$ \\
\hline & Transfer & 134 & 94 & $70 \%$ \\
\hline
\end{tabular}

.Table 3. Multi-Engine Training Completion Rates for Native and Transfer Students

\begin{tabular}{|c|c|c|c|c|c|}
\hline Semester & Trans Status & Enrolled & Completed & Active & $\%$ Complete \\
\hline \multirow[t]{2}{*}{ Fall 1998} & Native & 27 & 11 & & $41 \%$ \\
\hline & Transfer & 13 & 7 & & $54 \%$ \\
\hline \multirow[t]{2}{*}{ Spring 1999} & Native & 20 & 8 & & $40 \%$ \\
\hline & Transfer & 9 & 2 & & $22 \%$ \\
\hline \multirow[t]{2}{*}{ Summer 1999} & Native & 2 & 2 & & $100 \%$ \\
\hline & Transfer & 2 & 2 & & $100 \%$ \\
\hline \multirow[t]{2}{*}{ Fall 1999} & Native & 22 & 5 & & $23 \%$ \\
\hline & Transfer & 19 & 9 & & $47 \%$ \\
\hline \multirow[t]{2}{*}{ Spring 2000} & Native & 19 & 12 & & $63 \%$ \\
\hline & Transfer & 5 & 3 & & $60 \%$ \\
\hline \multirow[t]{2}{*}{ Summer 2000} & Native & 2 & 1 & & $50 \%$ \\
\hline & Transfer & 4 & 3 & & $75 \%$ \\
\hline \multirow[t]{2}{*}{ Fall 2000} & Native & 11 & 6 & & $55 \%$ \\
\hline & Transfer & 12 & 5 & & $42 \%$ \\
\hline \multirow[t]{2}{*}{ Spring 2001} & Native & 17 & 11 & & $65 \%$ \\
\hline & Transfer & 1 & 1 & & $100 \%$ \\
\hline \multirow[t]{2}{*}{ Summer 2001} & Native & 0 & 0 & & \\
\hline & Transfer & 3 & 1 & & $33 \%$ \\
\hline
\end{tabular}


Table 3. Multi-Engine Training Completion Rates for Native and Transfer Students Continued

\begin{tabular}{|c|c|c|c|c|c|}
\hline Semester & Trans Status & Enrolled & Completed & Active & $\%$ Complete \\
\hline \multirow[t]{2}{*}{ Fall 2001} & Native & 7 & 4 & & $57 \%$ \\
\hline & Transfer & 26 & 17 & & $65 \%$ \\
\hline \multirow[t]{2}{*}{ Spring 2002} & Native & 19 & 12 & 1 & $63 \%$ \\
\hline & Transfer & 6 & 3 & & $50 \%$ \\
\hline \multirow[t]{2}{*}{ Summer 2002} & Native & 8 & 1 & & $13 \%$ \\
\hline & Transfer & 7 & 4 & & $57 \%$ \\
\hline \multirow[t]{2}{*}{ Fall 2002} & Native & 23 & 14 & & $61 \%$ \\
\hline & Transfer & 16 & 9 & & $56 \%$ \\
\hline \multirow[t]{2}{*}{ Spring 2003} & Native & 21 & 8 & 2 & $38 \%$ \\
\hline & Transfer & 11 & 6 & 1 & $55 \%$ \\
\hline \multirow[t]{2}{*}{ Summer 2003} & Native & 4 & 2 & & $50 \%$ \\
\hline & Transfer & 0 & 0 & & \\
\hline \multirow[t]{2}{*}{ Totals } & Native & 202 & 97 & 3 & $49 \%$ \\
\hline & Transfer & 134 & 72 & 1 & $54 \%$ \\
\hline
\end{tabular}

Table 4 displays mean days-to-degree of native and transfer students by semester. Daysto-degree was chosen as the appropriate measure for flight students due to the aviation flight program's policy, which allows students to begin and complete courses anytime during a semester. Days-to-degree were measured from the date of a student's first lesson in the initial instrument training course, until the date a student completed their multi-engine training graduation check flight. The mean days-todegree of transfer students was 829 , which was 44 days less than the mean of 873 for native students. However, the mean days-to-degree for native students is skewed higher because of the fall 1998 semester when five students took six or more semesters to complete multi-engine training. If the fall 1998 semester was removed from the population, the mean days-to-degree of native students would be 838 days.

Table 4. Mean Days-to-degree of Native and Transfer Students by Semester

\begin{tabular}{llcc}
\hline Semester & Transfer Status & Days-to-degree & Stan. Dev. \\
\hline Fall 1998 & Native & 1144 & 383 \\
\multirow{3}{*}{ Spring 1999 } & Transfer & 892 & 180 \\
& Native & 755 & 109 \\
Summer 1999 & Transfer & 682 & 74 \\
& Native & 953 & 50 \\
Fall 1999 & Transfer & 668 & 33 \\
& Native & 965 & 251 \\
Spring 2000 & Transfer & 851 & 276 \\
& Native & 854 & 253 \\
Summer 2000 & Transfer & 940 & 261 \\
& Native & 665 & \\
Fall 2000 & Transfer & 771 & 128 \\
& Native & 941 & 204 \\
\hline
\end{tabular}




\begin{tabular}{llcc}
\hline \multicolumn{4}{l}{ Table 4. Mean Days-to-degree of Native and Transfer Students by Semester- Continued } \\
\hline Semester & Transfer Status & Days-to-degree & Stan. Dev. \\
\hline Spring 2001 & Native & 709 & 99 \\
& Transfer & 850 & \\
Summer 2001 & Native & & \\
& Transfer & 1032 & 157 \\
Fall 2001 & Native & 664 & 116 \\
& Transfer & 841 & 215 \\
Spring 2002 & Native & 921 & 142 \\
& Transfer & 624 & \\
Summer 2002 & Native & 1239 & 262 \\
& Transfer & 745 & 239 \\
Fall 2002 & Native & 839 & 148 \\
& Transfer & 809 & 163 \\
Spring 2003 & Native & 842 & 81 \\
& Transfer & 795 & 88 \\
Summer 2003 & Native & 785 & \\
& Transfer & & 251 \\
Totals & Native & 873 & 185 \\
& Transfer & 829 & \\
\hline
\end{tabular}

Table 5 displays the number of proficiency and direct-entry transfer private pilots by semester. Proficiency students are transfer students that took some form of screening training and/or a check ride prior to beginning instrument training, whereas direct-entry students enrolled immediately in instrument training upon admission to the flight program. The study population consists of a total of 78 direct-entry students and 56 proficiency students. Between the spring 1999 semester and fall 2002 semester, there was a proficiency requirement, but nine students had the requirement waived because these students had their private pilot check ride with an Assistant Professor Emeritus from the flight program.

Table 6 displays the instrument training completion rates of proficiency and direct-entry transfer students. Direct-entry transfer students had an instrument training completion rate of $74 \%$, while proficiency students had a $64 \%$ completion rate.

Table 7 displays multi-engine training completion rates of proficiency and direct-entry transfer students. Direct-entry students had a $57 \%$ completion rate, whereas proficiency students had a $50 \%$ completion rate. There was one direct-entry transfer student that was still active in the flight program when the data was gathered. The completion percentage was calculated by subtracting the active student from the total enrolled. If this student were to complete or fail, the completion percentage would be affected by less than $1 \%$.

Table 8 displays mean days-to-degree for proficiency and direct-entry transfer students. The number of days-to-degree was measured from the date of the first lesson in the initial instrument training course until the date the multi-engine graduation check flight was completed. Direct-entry students used 831 mean days-to-degree compared to 825 days for proficiency students. Proficiency training is not included in the days-to-degree calculation. This may account for proficiency students taking fewer than six days. If any remedial training was required for direct-entry students, it would have to be completed in the initial instrument training course.

\section{Research Question One}

Is there a difference in the successful completion of instrument flight training between students who earn their private pilot's license at the university and those who complete their private pilot training elsewhere? 
Table 5. Number of Proficiency and Direct-Entry Transfer Students by Semester

\begin{tabular}{lccc}
\hline Semester & Direct & Proficiency & Total \\
\hline Fall 1998 & 0 & 13 & 13 \\
Spring 1999 & 3 & 6 & 9 \\
Summer 1999 & 0 & 2 & 2 \\
Fall 1999 & 3 & 16 & 19 \\
Spring 2000 & 1 & 4 & 5 \\
Summer 2000 & 1 & 3 & 4 \\
Fall 2000 & 1 & 11 & 12 \\
Spring 2001 & 0 & 1 & 1 \\
Summer 2001 & 3 & 0 & 3 \\
Fall 2001 & 26 & 0 & 26 \\
Spring 2002 & 6 & 0 & 6 \\
Summer 2002 & 7 & 0 & 7 \\
Fall 2002 & 16 & 0 & 16 \\
Spring 2003 & 11 & 0 & 11 \\
Summer 2003 & 0 & 0 & 0 \\
\hline Totals & 78 & 56 & 134 \\
\hline
\end{tabular}

Table 6. Instrument Training Completion Rates for Proficiency and Direct-Entry Transfer Students

\begin{tabular}{lccc}
\hline Type of Entry & Total Enrolled & Completed & \% Completed \\
\hline Direct & 78 & 58 & $74 \%$ \\
Proficiency & 56 & 36 & $64 \%$ \\
\hline Total & 134 & 94 & \\
\hline
\end{tabular}

Table 7. Multi-Engine Training Completion Rates for Proficiency and Direct-Entry Transfer Students

\begin{tabular}{lrrrrr}
\hline Type of Entry & Total Enrolled & Completed & Active & \multicolumn{2}{c}{$\%$ Completed } \\
\hline Direct & 78 & 44 & 1 & $57 \%$ \\
Proficiency & 56 & 28 & 0 & $50 \%$ \\
\hline Total & 134 & 72 & 1 & \\
\hline
\end{tabular}

Table 8. Mean Days-to-degree for Proficiency and Direct-Entry Transfer Students

\begin{tabular}{lccc}
\hline Type of Entry & Days-to-degree & Completed & Standard Deviation \\
\hline Direct & 831 & 44 & 165 \\
Proficiency & 825 & 28 & 216
\end{tabular}


Table 9. Chi-Square for Instrument Training Completion by Transfer Status

\begin{tabular}{|c|c|c|c|c|}
\hline Transfer Status & Count & Completed & Incomplete & Total \\
\hline \multirow[t]{2}{*}{ Native } & Observed & 134 & 67 & 201 \\
\hline & Expected & 137 & 64 & 201 \\
\hline \multirow[t]{2}{*}{ Transfer } & Observed & 95 & 40 & 135 \\
\hline & Expected & 92 & 43 & 135 \\
\hline Chi-Square & 0.51 & & Sig. & 3.84 \\
\hline
\end{tabular}

$\mathrm{p}<.05$

In Table 9, the observed and expected instrument training completion frequencies of native and transfer private pilots in the flight program were compared using chi-square. Chisquare was calculated to be 0.51 , which is less than 3.84 that is required to be significant $(p<.05)$. Therefore, there is no statistically significant difference in instrument training completion rates between native and transfer private pilots in the flight program.

\section{Research Question Two}

Is there a difference in the successful completion of multi-engine training between students who earn their private pilot's license at the university and those who complete their private pilot training elsewhere?

Table 10. Chi-Square for Multi-Engine Training Completion by Transfer Status

\begin{tabular}{|c|c|c|c|c|}
\hline Transfer Status & Count & Completed & Incomplete & Total \\
\hline \multirow[t]{2}{*}{ Native } & Observed & 96 & 103 & 199 \\
\hline & Expected & 101 & 98 & 199 \\
\hline \multirow[t]{2}{*}{ Transfer } & Observed & 73 & 61 & 134 \\
\hline & Expected & 68 & 66 & 134 \\
\hline Chi-Square & 1.246 & & Sig. & 3.84 \\
\hline
\end{tabular}

$p<.05$

In Table 10, the observed and expected multi-engine training completion frequencies of native and transfer private pilots in the flight program were compared using chi-square. Chisquare was calculated to be 1.246 , which is less than 3.84 that is required to be significant $(\mathrm{p}<.05)$. Therefore, there is no statistically significant difference in multi-engine training completion rates between native and transfer private pilots in the flight program.

\section{Research Question Three}

Is there a difference in days-to-degree between students that complete their private pilot's license at the university and those who complete their private pilot training elsewhere?

Table 11..T-Test for Days-to-degree by Transfer Status

\begin{tabular}{|c|c|c|c|}
\hline Transfer Status & $\mathrm{N}$ & Mean & SD \\
\hline Native & 96 & 875.5 & 251.5 \\
\hline Transfer & 73 & 826.5 & 184.6 \\
\hline Total & 169 & & \\
\hline $\mathrm{t}$ & 1.401 & Sig. & 1.96 \\
\hline Df & 167 & & \\
\hline
\end{tabular}

$\mathrm{p}<.05$

Days-to-degree was chosen as the measure of time-to-degree due to students' ability to enroll, begin and end flight courses at anytime during a semester. In Table 11, a t-test of independent samples was used to determine significant differences in days-to-degree of native and transfer students. A value of 1.401 was calculated for $\mathrm{t}$, which is less than the $\mathrm{t}$ value of 1.96 required for significance $(p<.05)$. Therefore, there is no statistically significant difference in days-to-degree between native and transfer private pilots in the flight program. 


\section{Research Question Four}

Is there a difference in the successful completion of instrument flight training between transfer private pilots who enter directly into instrument training and those whom must take proficiency or evaluation training?

Table 12. Chi-Square for Instrument Training Completion for Transfer Private Pilots by Type of

\begin{tabular}{|c|c|c|c|c|}
\hline & & & & \\
\hline \multirow{2}{*}{ Direct } & Observed & 58 & 20 & 78 \\
\hline & Expected & 54.7 & 23.3 & 78 \\
\hline \multirow[t]{2}{*}{ Proficiency } & Observed & 36 & 20 & 56 \\
\hline & Expected & 39.3 & 16.7 & 56 \\
\hline Chi-Squar & & & Sig. & 3.84 \\
\hline
\end{tabular}

$\mathrm{p}<.05$

In Table 12, the observed and expected instrument training completion frequencies of direct-entry and proficiency transfer private pilots in the flight program were compared using chi-square. Chi-square was calculated to be 1.58 , which is less than 3.84 that is required to be significant $(p<.05)$. Therefore, there is no statistically significant difference in instrument training completion rates between direct-entry and proficiency transfer private pilots in the flight program.

\section{Research Question Five}

Is there a difference in the successful completion of multi-engine training between transfer private pilots who enter directly into instrument training and those whom must take proficiency or evaluation training?

Table 13. Chi-Square for Multi-Engine Training Transfer Private Pilots by Type of Entry

\begin{tabular}{|c|c|c|c|c|}
\hline Type of Entry & Count & Completed & Incomplete & Total \\
\hline \multirow[t]{2}{*}{ Direct } & Observed & 44 & 33 & 77 \\
\hline & Expected & 41.7 & 35.3 & 77 \\
\hline \multirow{2}{*}{ Proficiency } & Observed & 28 & 28 & 56 \\
\hline & Expected & 30.3 & 25.7 & 56 \\
\hline Chi-Square & 0.666 & & Sig. & 3.84 \\
\hline
\end{tabular}

$\mathrm{p}<.05$

In Table 13, the observed and expected multi-engine training completion frequencies of direct-entry and proficiency transfer private pilots in the flight program were compared using chi-square. Chi-square was calculated to be 0.666 , which is less than 3.84 that is required to be significant $(\mathrm{p}<.05)$. Therefore, there is no statistically significant difference in multiengine training completion rates between directentry and proficiency transfer private pilots in the flight program.

\section{Research Question Six}

Is there a difference in days-to-degree between transfer private pilots who enter directly into instrument training and those whom must take proficiency or evaluation training?
In Table 14, a t-test of independent samples was used to determine significant differences in days-to-degree of direct-entry and proficiency transfer students in the flight program. A value of 0.136 was calculated for $t$, which is less than the $\mathrm{t}$ value of 1.96 required for significance $(p<.05)$. Therefore, there is no statistically significant difference in days-to-degree between direct-entry and proficiency transfer students in the flight program. 
Table 14. T-Test of Days-to-degree for Transfer Private Pilots by Type of Entry

\begin{tabular}{|c|c|c|c|}
\hline Type of Entry & $\mathrm{N}$ & Mean & SD \\
\hline Direct & 44 & 831 & 164.7 \\
\hline Proficiency & 28 & 824.9 & 216.2 \\
\hline Total & 72 & & \\
\hline $\begin{array}{c}t \\
D f\end{array}$ & $\begin{array}{c}0.136 \\
70\end{array}$ & Sig. & 1.96 \\
\hline
\end{tabular}

\section{DISCUSSION}

The purpose of this study was to research factors concerning transfer and native student's successful completion of the Aviation Flight Degree. The topic of native and transfer private pilots was chosen due to the lack of similar research in collegiate aviation. Federal Aviation Regulation Parts 61 and 141 schools were discussed to show different training environments from which transfer private pilots could come. The U.S. military has had many versions of initial pilot training, ranging from civilian training to complete in-house training, both of which exhibited little difference in the completion rates.

Data for this study was collected on a population of 336 aviation flight students that began instrument training between the fall 1998 and summer 2003 semesters. The data shows that there is no significant difference between native and transfer private pilots as well as no significant differences between direct-entry and proficiency transfer private pilots in the flight program.

\section{CONCLUSIONS AND RECOMMENDATIONS}

Based on the results of the data analysis, the following conclusions may be drawn: When comparing days-to-degree, instrument rating completion and degree completion, there were no statistically significant differences between native and transfer private pilots for the study's time period. A pilot's transfer status does not appear to be a good indicator of student success in the Aviation Flight Program.

When comparing days-to-degree, instrument rating completion and degree completion, there were no statistically significant differences between transfer private pilots that directly entered instrument training and those required to pass an evaluation or receive proficiency training. For the study's time period, proficiency training and testing do not appear to be a good indicator of student success in the Aviation Flight Program.

Based on the results of this study and the findings, the following recommendations can be made: Future research should be conducted on the effectiveness of the current Private Pilot Transition Course as a transitioning tool for transfer private pilots in the flight program. Further research should be conducted on factors that effect program completion and time-todegree for collegiate aviation flight students. 


\section{REFERENCES}

Hansen J. S., \& Oster, C. V. (Eds.). (1997). Taking flight: Education and training for aviation careers. Washington, DC: National Academy Press.

Part 61 versus part 141. (2002). Retrieved July 26, 2005, from http://www.ufly.com/articles/61v141.html

U.S. Department of Transportation, Federal Aviation Administration. (2003). FAA certificated pilot schools. Advisory circular 140-2FF.

U.S. Department of Transportation, Federal Aviation Administration, Flight Standards Service. (2004). Airplane flying handbook. (FAA Publication No. FAA-H-8083-3A). Oklahoma City: Author. 